\title{
Analysis of Preservative Capacity for Contemporary Iranian Shampoos
}

\author{
Marzieh Miranzadeha, Mohammad Zaman Kassaee ${ }^{\mathrm{a}, *}$, Leila Sadeghi ${ }^{\mathrm{b}}$
}

\section{AR T I C L E I N F O \\ Received: 20 November 2018 \\ Revised: 12 December 2018 \\ Accepted: 28 December 2018 \\ Available online: 6 January 2019}

\section{K E Y W O R D S}

Preservative

Iranian Shampoos

E. coli

S. aureus

P. aeruginosa

MRSA

\begin{abstract}
A B S T R A C T
Preservative capacity is measured for seventeen currently accessible Iranian made shampoo products. Upon purchase, bacterial counts show no trace of any microbial contamination. The shampoo bottles are distributed to seventeen female graduate students, residing at the time in different dormitories of Tarbiat Modares University (TMU). After 40 days, the allocated bottles are returned and their bacterial counts repeated, under the same conditions. To our surprise, no trace of any microbial contamination is observed. Three possibilities are considered. 1) The factory employed preservative(s) act very efficiently. 2) The shampoo component(s) are themselves bactericidal. 3) Existence of sanitary conditions and the absence of any microbial contaminants at TMU! Evidently, the third possibility is ruled out. The second choice is also discarded, because practically no significant antimicrobial activity is demonstrated by any of the four main ingredients of the shampoos including sodium lauryl ether sulfate (SLES), betaine, coconut fatty acid, and glycerin. Hence, the most likely possibility is the first one, since upon deliberate contamination of the seventeen brands; the factory employed preservatives [5-chloro-2-methyl-4isothiazolin-3-one and 2-methyl-4-isothiazolin-3-one (KATHON CG)] prove highly bactericidal against four major contaminants: Escherichia coli, Staphylococcus aureus, Pseudomonas aeruginosa, and the methicillin-resistant Staphylococcus aureus (MRSA).
\end{abstract}

GR A P H I C A L A B S T RACT

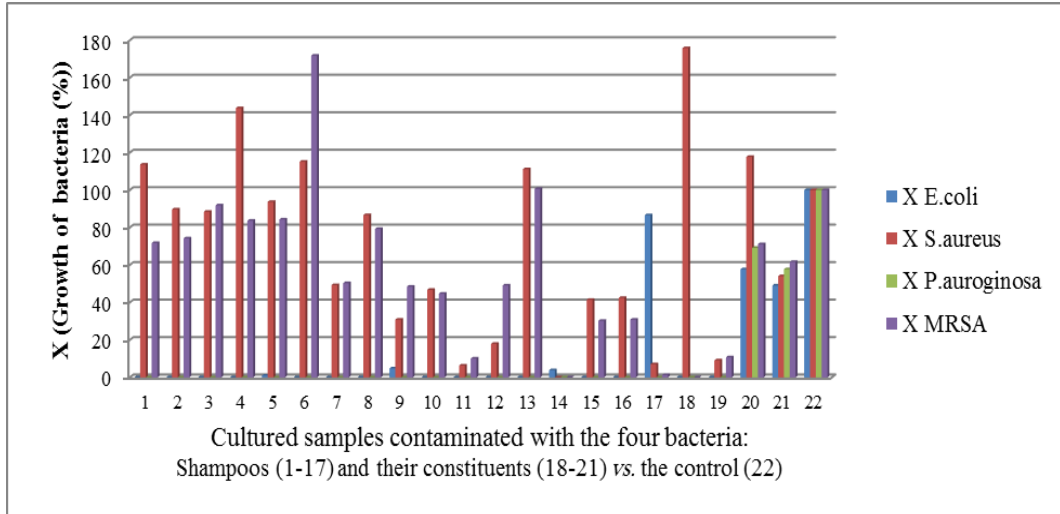

*Corresponding author's E-mail address: kassaeem@modares.ac.ir, Tel.: 00982182883441 Fax: 0098 2188009730

a Department of Chemistry, Tarbiat Modares University, P.O. Box 14155-4838, Tehran, Iran.

b Kimya Faraz Zibae Co., Tehran, Iran. 


\section{Introduction}

Soaps are among surfactants that make up detergents which appear in forms of liquid, powder, paste, bar, cake, molded piece, etc. [1]. Surfactants may be applied in household laundry products, domestic and industrial cleaners, cosmetic products, shampoo formulations, etc. They are capable of forming micelles because of their hydrophilic and hydrophobic groups [2, 3]. As a result, they help achieve cleaning, rinsing, and fabric softening due to the above mentioned surface-active properties $[4,5]$.

About $70-80 \%$ of the entire weight of most detergents is water. The rest is the primary surfactant, followed by the foam boaster, thickeners, conditioning agents, modifiers, and desired additives [6, 7]. While, the sterility of shampoo is not often required; contamination with pathogenic microorganisms and microbial contaminants appear unavoidable [8]. Microorganisms such as E. coli, S. aureus, and $P$. aeruginosa easily grow in places that are not often completely dried, for instance: bathtubs, shower areas, kitchen counters, sinks, etc. [9]In such places, microbes can easily be transmitted to shampoos, soaps, towels, and the like. A number of shampoo preparations employed in this work are based on sodium laurylsulphate surfactants that separate or discolor upon proliferation of Pseudomonas species [10]. Of special concern is the detection of the latter opportunistic pathogen that has spoilage potentials and is the most common microorganism associated with recall of many cosmetic formulations in the United States and Europe [7, 11-12]. As a rule of thumb, bacterial count in the products must be low with no pathogen. What isso alarming to usis the report on the $43 \%$ rate of microbial contamination of shampoo brands marketed in some countries [13].In one instance, three babies in a nursery became infected with Serratia marcescens, purulent conjunctivitis (two cases) and omphalitis (one). Thirteen of fourteen babies recovered fully but one died from $S$. marcescens meningitis and septicaemia. All infections were traced to intrinsically contaminated baby shampoo introduced to the units five days before the first reported case [14-15].

In another instance, the microbiological quality of sixteen different shampoo formulations (manufactured by sixteen different factories) was studied to determine the preservative capacity of these products at a time of sale and after use. Procedures used were according to those described in ISO technical standards. Thirteen (81.25\%) of the formulations studied were found to be free of 
contamination. One product harbored E. coli and two contained P. aeruginosa [15-16].

In another instance, 8 commercial brands of shampoo were studied and none of them harbored microorganisms in access of $10^{4}$ $\mathrm{CFU} / \mathrm{mL}$. Only $15 \%$ of the products revealed bacterial count between $10^{2}$ to $10^{3}$ cells $/ \mathrm{mL}$ [13-15].

Finally, Staphylococcus, Pseudomonas, Klebsiella, Achromobacter and Alcaligene were detected in shampoo, hand and body lotion, facial cleanser, and liquid soaps [1517].

So, microbial contamination of shampoo products is very common and appears of great concern. Microorganisms can cause health hazards because their metabolic products may be toxic and/or mutagenic. Hence, in order to guarantee long-term stability, shampoo formulations need protection against microbial spoilage. This may be in the form of preservatives which play a vital role in the product formulations $[12,17]$.

Among preservatives KATHON CG is the most common. Its active ingredients are two isothiazolinones, including 5-chloro-2methyl-4-isothiazolin-3-one and 2-methyl4-isothiazolin-3-one [18].

As a service to the community, in this work durability of Iranian shampoo formulations are probed at the time of sale and after 40 days (or usage of $2 / 3$ of their bottles, whichever comes first). In addition, the shampoo products are tested against deliberate contaminations to E. coli, S. aureus, $P$. aeruginosa, and MRSA.

\section{Experimental}

\section{Materials and Methods}

The probed shampoos are purchased directly from their Iranian manufactures. In conformity with the publisher nonsolicitation regulations, each brand is given a numerical code (1-17) prior to the experimental work. Bacteria sues are obtained from the Bacteriology Department, Faculty of Medical Sciences, TMU. MullerHilton agar is purchased from Liophil Chem Company, Italy. Brain-Hearb Infusion (BHI) agar is purchased from Merck Company, Germany. The seventeen human subjects are selected from volunteer female graduate students residing at the TMU dormitories (ages 22-28).

To determine whether 1-17 are initially germ-free, four $100 \mu \mathrm{L}$ specimens of each brand are probed: one at the normal concentration and three others with serial dilutions at $0.1,0.01$, and $0.001 \mathrm{v} / \mathrm{v}$ in normal saline ( $\mathrm{NaCl} 93 \%)$. Hence, a total of sixty eight samples are simultaneously cultured. Each sample is transferred to a sterile Petri dish containing $20 \mathrm{~mL}$ BHI agar and incubated at $35^{\circ} \mathrm{C}$ for 48 hours. Surprisingly, 
all the latter shampoo samples prove totally germ-free.

Consecutively, these seventeen microbial free shampoo samples, 1-17, are assigned to seventeen female graduate students, residing at the time in different dormitories of TMU. The samples are recollected after 40 days, or as soon as the residual quantity in each container becomes approximately $1 / 3$ of its original volume. Repeating the above microbial test for each sample shows no microbial contamination under normal conditions.

To expand on the preservative capacity of the above normally durable shampoos, 1-17 are tested against deliberate bacterial contaminations with E. coli, S. aureus, $P$. aeruginosa, and MRSA. Similarly the four major constituents of shampoos including: SLES, betaine, coconut fatty acid, and glycerin (18-21) are contaminated. Specifically, each of the above mentioned bacterial strains is cultured overnight on Muller-Hilton agar (ATCC, WDCM1). A suspension of each is prepared in $5 \mathrm{~mL}$ normal saline containing $10^{9}$ cells $/ \mathrm{mL}$. These suspensions $(100 \mu \mathrm{L})$ are mixed and homogenized separately with $500 \mu \mathrm{L}$ shampoo products 1-17 and their constituents 18-22. After a specific time, 5 $\mathrm{mL}$ sterile normal saline is added to these mixtures and vortexed for one minute. Dilutions of each tube are cultured on
Muller-Hilton agar. The plates are maintained at $37{ }^{\circ} \mathrm{C}$ for 18 hours then number of colonies per sample is counted.

\section{Results and Discussion}

Codes of standards on Iranian manufactured shampoos (No. 3271, ICS: 07.100.99; 71.100.70) require total absence of E. coli, $S$. aureus, and $P$. aeruginosa with no more than $10^{2} \mathrm{CFU} / \mathrm{mL}$ of mesophilic aerobic bacteria [19]. One of our main objectives in this work is to find if all seventeen contemporary Iranian manufactured shampoos (1-17) comply with the above regulation.

First of all, to determine whether the shampoo products are germ-free at purchase, four $100 \mu \mathrm{L}$ specimens of each brand are simultaneously cultured in agar. They include one at normal concentration and three others with serial dilutions at 0.1 , $0.01,0.001 v / v$ in normal saline ( $\mathrm{NaCl} 93 \%)$. Hence, in this part of our work, a total of 68 samples are simultaneously incubated. Specifically, each sample is transferred to a sterile Petri dish containing $20 \mathrm{~mL}$ BHI agar and incubated at $35{ }^{\circ} \mathrm{C}$ for 48 hours. The results of the first part of our survey come out rather surprising, because samples appear totally germ-free!

Consecutively, in the second part of our work, these seventeen microbial free shampoo samples 1-17 are assigned to seventeen 22-28 years old female graduate 
students, residing at the time in different dormitories of TMU. The samples are recollected after 40 days, or as soon as the residual quantity in each container becomes approximately $1 / 3$ of its original volume. Repeating the above microbial test for each sample results in another surprise for us, sinceno microbial contamination is found under normal conditions! Looking for good explanations for the above observations one finds several factors which prevent microbial contamination of shampoos. For example, Branna and Dille established that the dispensing closure used for shampoo and cosmetic containers play an important role in protecting them from in-use microbial contaminations [20]. All things considered, we adoptthe following three possibilities: 1) The factory employed preservative(s) may act very efficiently. 2) The shampoo component(s) (18-21) maybe bactericidal. 3) TMU dormitories are perhaps free of microbial contaminants. Evidences, at least in two universities similar to TMU, rule out the third possibility $[21,22]$. The second possibility is also discarded, because the four main ingredients of the shampoos including sodium lauryl ether sulfate (SLES), betaine, coconut fatty acid, and glycerin show no significant antimicrobial activity. The only possibility left among the three goes back the first choice: The factory employed preservative(s) may act very efficiently.

This brings us to the third part of our work, which is to probe the above possibility. Hence, the seventeen shampoo brands (Samples 1-17), plus their four main constituents (Samples 18-21) are separately contaminated with four strains of bacteria including E. coli, S. aureus, P. aeruginosa, and the MRSA. Prior to such contaminations, each of the above mentioned bacterial strains is cultured overnight on MullerHilton agar, from which four suspensions are made, each in $5 \mathrm{~mL}$ normal saline containing $10^{9}$ cells $/ \mathrm{mL}$. Then $100 \mu \mathrm{L}$ of each of the latter suspensions of bacteria is separately added to $500 \mu \mathrm{L}$ of each of the seventeen shampoo samples (1-17), as well as to $500 \mu \mathrm{L}$ aliquots of each of the four shampoo constituents Consequently, the above samples are homogenized. After a 24 hours, $5 \mathrm{~mL}$ sterile normal saline is added to these mixtures and vortexed for one minute. Three dilutions of each sample $(1,0.1$, and $0.01 v / v)$ are cultured on Muller-Hilton agar. The plates are maintained at $37^{\circ} \mathrm{C}$ for 18 hours then the number of colonies per sample is counted. The overnight vicinity (24 hours) shampoo samples extirpate all of the bacteria. Hence, vicinage time is gradually decreased and experiments are repeated down to 12 and then 6 hours, where all the bacteria are 
similarly extirpated. So the time is decreased again. After 30 minutes and in dilution of $0.01 \mathrm{v} / \mathrm{v}$ alterations are observable and results are recorded (Table 1). Quantitatively, these results are based on the percent bacterial growth $(\mathrm{X})$, which is shown by $\mathrm{X}=(1-((\mathrm{B}-\mathrm{T}) / \mathrm{B})) * 100$. Here, $\mathrm{B}$ is the number of colonies in a bacterial assay used as the "Control" (Sample 22). "Control" is attributed to every one of the four strains of bacterial directly cultured on agar, without being subjected to the shampoo formulations (1-17) or their constituents (18-21). Finally, $\mathrm{T}$ is the number of colonies found in either one of the seventeen shampoo samples (1-17), or the four shampoo constituents (18-21).

Table1. E. coli, S. aureus, P. aeruginosa, and MRSA growth percentages (X), upon thirty minutes adjacency to seventeen shampoo samples (1-17), along with four shampoo constituents (18-21), in comparison to the corresponding control bacterial assays not exposed to the shampoo formulations or their constituents (Sample 22)

\begin{tabular}{|c|c|c|c|c|c|}
\hline \multirow{2}{*}{\multicolumn{2}{|c|}{ Cultured samples }} & \multicolumn{4}{|c|}{$\mathbf{X}$} \\
\hline & & E.coli & S.aureus & P.aeruginosa & MRSA \\
\hline \multirow{17}{*}{$\begin{array}{c}\text { Seventeen } \\
\text { contaminated } \\
\text { shampoo } \\
\text { formulations }\end{array}$} & 1 & 0 & 113.64 & 0 & 71.70 \\
\hline & 2 & 0 & 89.65 & 0 & 74.21 \\
\hline & 3 & 0 & 88.38 & 0 & 91.82 \\
\hline & 4 & 0 & 143.69 & 0 & 83.65 \\
\hline & 5 & 0.96 & 93.69 & 0 & 84.28 \\
\hline & 6 & 0 & 115.15 & 0 & 171.70 \\
\hline & 7 & 0 & 49.24 & 0 & 50.31 \\
\hline & 8 & 0 & 86.62 & 0 & 79.25 \\
\hline & 9 & 4.81 & 30.81 & 0 & 48.43 \\
\hline & 10 & 0 & 46.72 & 0 & 44.65 \\
\hline & 11 & 0 & 6.31 & 0 & 10.07 \\
\hline & 12 & 0 & 17.93 & 0 & 49.06 \\
\hline & 13 & 0 & 111.11 & 0 & 100.63 \\
\hline & 14 & 3.85 & 0 & 0 & 0 \\
\hline & 15 & 0 & 41.41 & 0 & 30.19 \\
\hline & 16 & 0 & 42.42 & 0 & 30.82 \\
\hline & 17 & 86.54 & 7.07 & 0 & 1.26 \\
\hline \multirow{4}{*}{$\begin{array}{c}\text { Four } \\
\text { contaminated } \\
\text { shampoo } \\
\text { constituents }\end{array}$} & 18 & 0 & 175.76 & 0 & 0 \\
\hline & 19 & 0 & 9.09 & 0 & 10.69 \\
\hline & 20 & 57.69 & 117.68 & 69.13 & 71.07 \\
\hline & 21 & 49.04 & 54.04 & 57.72 & 61.64 \\
\hline $\begin{array}{c}\text { Control } \\
\text { pure bacteria }\end{array}$ & 22 & 100.00 & 100.00 & 100.00 & 100.00 \\
\hline
\end{tabular}




\section{Contamination with $E$. coli}

E. coli growth percentages $\left(\mathrm{X}_{E}\right.$ coli $)$ are assessed after thirty minutes adjacency with shampoo samples (1-17) as well as their constituents (18-21). These are all measured against to the "Control", which is an E. coli assay, not subjected to the shampoo formulations or their constituents (Sample 22) (Figure 1, Table 1).

All Iranian manufactured shampoo formulations appear resistant to $E$. coli except for brands 5, 9, 14, and 17 which show $X_{E \text {. coli }}$ of $1,5,4$, and 86 , respectively. From four Iranian manufactured shampoo constituents, only SLES (Sample 18) and coconut fatty acid (Sample 19) appear resistant to E. coli. Hence, it is likely that shampoo 17 is composed mainly of betain and glycerin (Sample 20 and 21 respectively). If so, decreasing concentration of the latter may help its durability against E. coli. Therefore, we caution against using shampoo 17 in places contaminated with a high concentration of $E$. coli. Such places includes wimming pools with untreated water, contaminated surface water and groundwater, water-reservoirs polluted by animals and humans, everywhere that animals, particularly cows, sheep, and goats, livestock, etc. [23].

\section{Contamination with $S$. aureus}

S. aureus growth percentages $\left(\mathrm{X}_{\text {S. aureus }}\right)$ are evaluated after thirty minutes adjacency to shampoo samples (1-17) as well as their constituents (18-21). These are all measured relative to the "Control", which is a $S$. aureus assay not subjected to the shampoo formulations or their constituents (Sample 22) (Figure 2, Table 1).

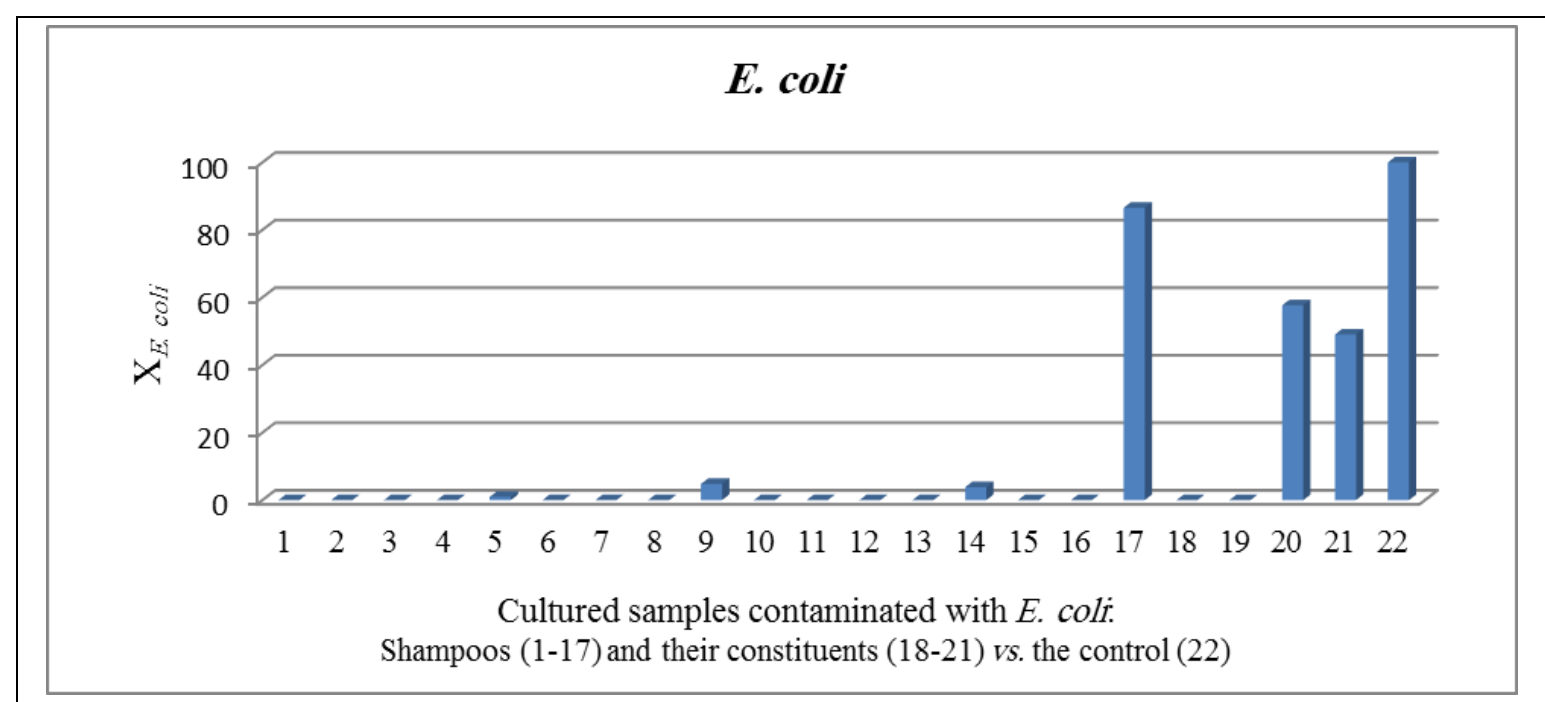

Figure 1. E. coli growth percentages $\left(\mathrm{X}_{E . \text { coli }}\right)$, upon thirty minutes adjacency to shampoo samples (117) or their constituents (18-21), all relative to the corresponding control bacterial assays not subjected to the shampoo formulations or their constituents (Sample 22) 


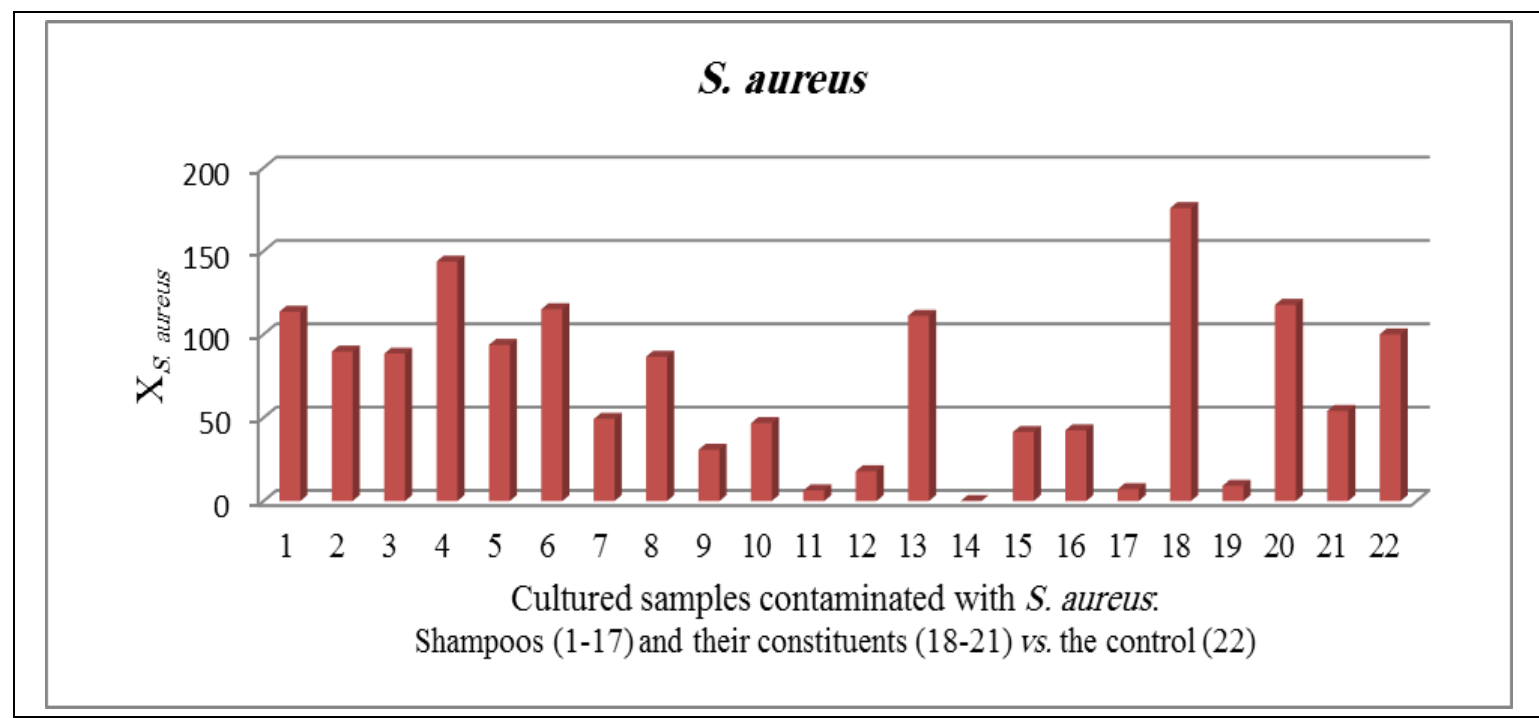

Figure 2. S. aureus growth percentages $\left(\mathrm{X}_{\text {S. aureus }}\right)$,upon thirty minutes adjacency to shampoo samples (1-17) or their constituents (18-21), all relative to the corresponding control bacterial assays not subjected to the shampoo formulations or their constituents (Sample 22)

Comparing E. coli with $S$. aureus, one finds the latter more potent for inducing rather high $\mathrm{X}_{S \text {. aureus }}$ for all samples except 14 . Interestingly, SLES (Sample 18), which is one of the four constituents of shampoo formulations, totally eliminates $E$. coli while not only it fails to eliminate $S$. aureus, butit stimulates its growth. Therefore, among 1-17 we recommend shampoo 14 to be employed in places contaminated with high concentration of S. aureus. Such places include wimming pools, gyms, wrestling locker rooms, etc. [24].

\section{Contamination with $P$. aeruginosa}

P. aeruginosa growth percentages $\left(\mathrm{X}_{P}\right.$. aeruginosa) are assessed after thirty minutes adjacency to shampoo samples (1-17) as well as their constituents (18-21). These are all assessed relative to the "Control", which is a $P$. aeruginosa assay not subjected to the shampoo formulations or their constituents (Sample 22) (Figure 3, Table 1).

Perhaps $P$. aeruginosais the least potent among the probed bacteria, because all Iranian manufactured shampoo formulations emerge resistant to it. From the constituents, SLES (Sample 18) and coconut fatty acid (Sample 19) appear resistant to it. So, all seventeen samples (1-17) score the best against $P$. aeruginosa. Hence, Iranian shampoos are recommended to be used in areas contaminated with $P$. aeruginosa. These areas include: Hospitals, swimming pools, 


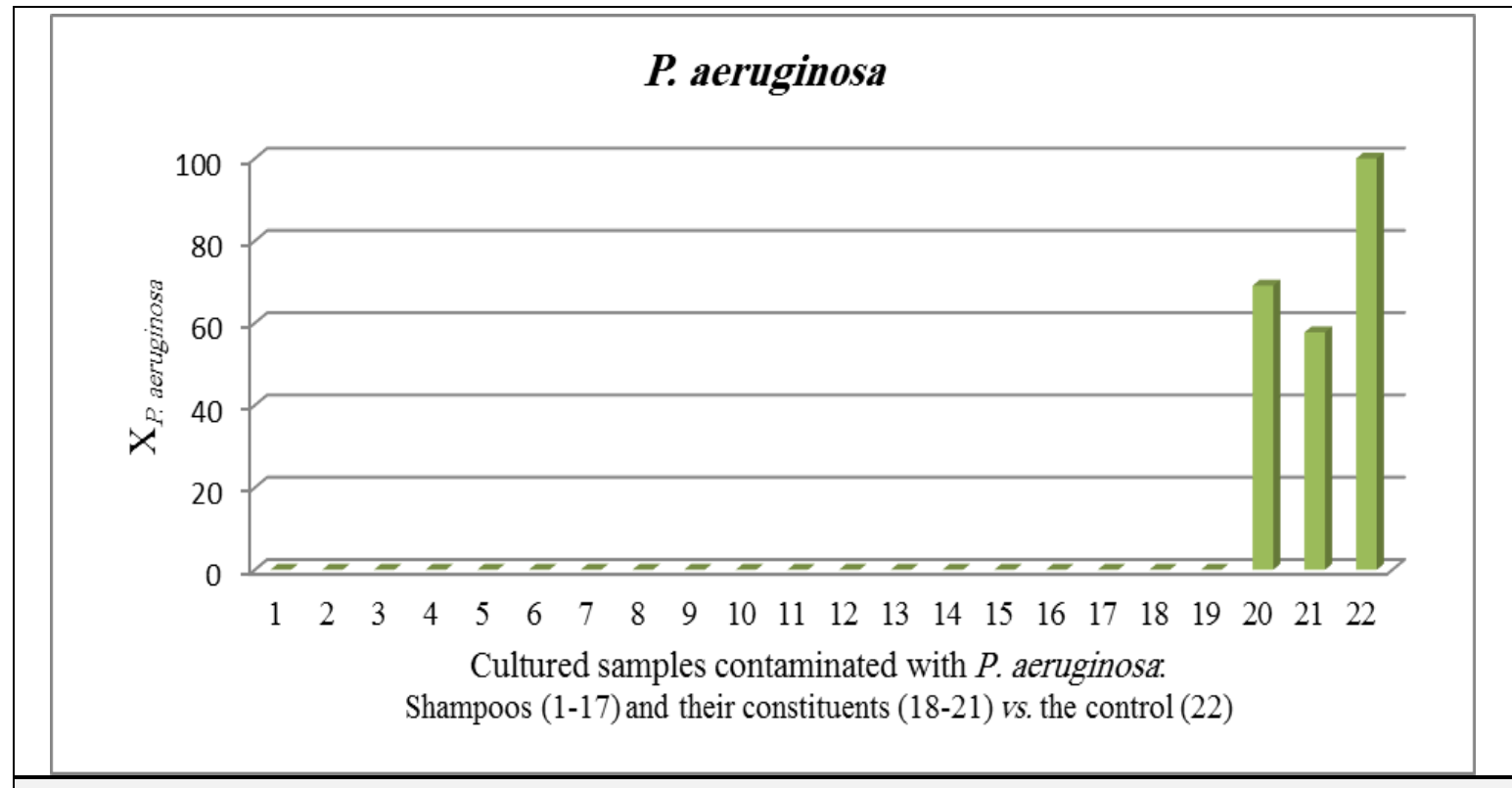

Figure 3. P. aeruginosa growth percentages $\left(\mathrm{X}_{P \text {. aeruginosa }}\right)$, upon thirty minutes adjacency to shampoo samples (1-17) or their constituents (18-21), all relative to the corresponding control bacterial assays not subjected to the shampoo formulations or their constituents (Sample 22)

\section{Contamination with the MRSA}

The $M R S A$ growth percentages $\left(\mathrm{X}_{M R S A}\right)$ are measured after thirty minutes adjacency to shampoo samples (1-17) as well as their constituents (18-21). These are all assessed relative to the "Control", which is a MRSA assay not subjected to the shampoo formulations or their constituents (Sample 22) (Figure 4, Table 1).

Between the samples (1-21) probed only shampoo 14 and constituent 18 show resistance to MRSA. Interestingly, SLES (18) cannot eliminate $S$. aureus but demonstrates significant bactericidal ability against the more potent MRSA (Figure 5). Similarly and to our surprise,
1-2, 4-5, 8, 10, 13, 15-16, and 20 eradicate MRSA more than S. aureus. Hence, we recommend usage of shampoo 14 in places contaminated with MRSA. Such places include hospitals, prisons, and nursing homes, etc. [26].

Finally, deliberate contamination of Iranian shampoo formulations and their constituents with $10^{9}$ bacteria (E. coli, S. aureus, P. aeruginosa, and MRSA) illustrate the products can eliminate contaminants during 1 hour and the constituents cannot act efficiently to eradicate all bacteria strains. So, preservatives including 5-chloro-2methyl-4-isothiazolin-3-one and 2methyl-4-isothiazolin-3-one (KATHON 
CG) prove highly bactericidal against contaminants.

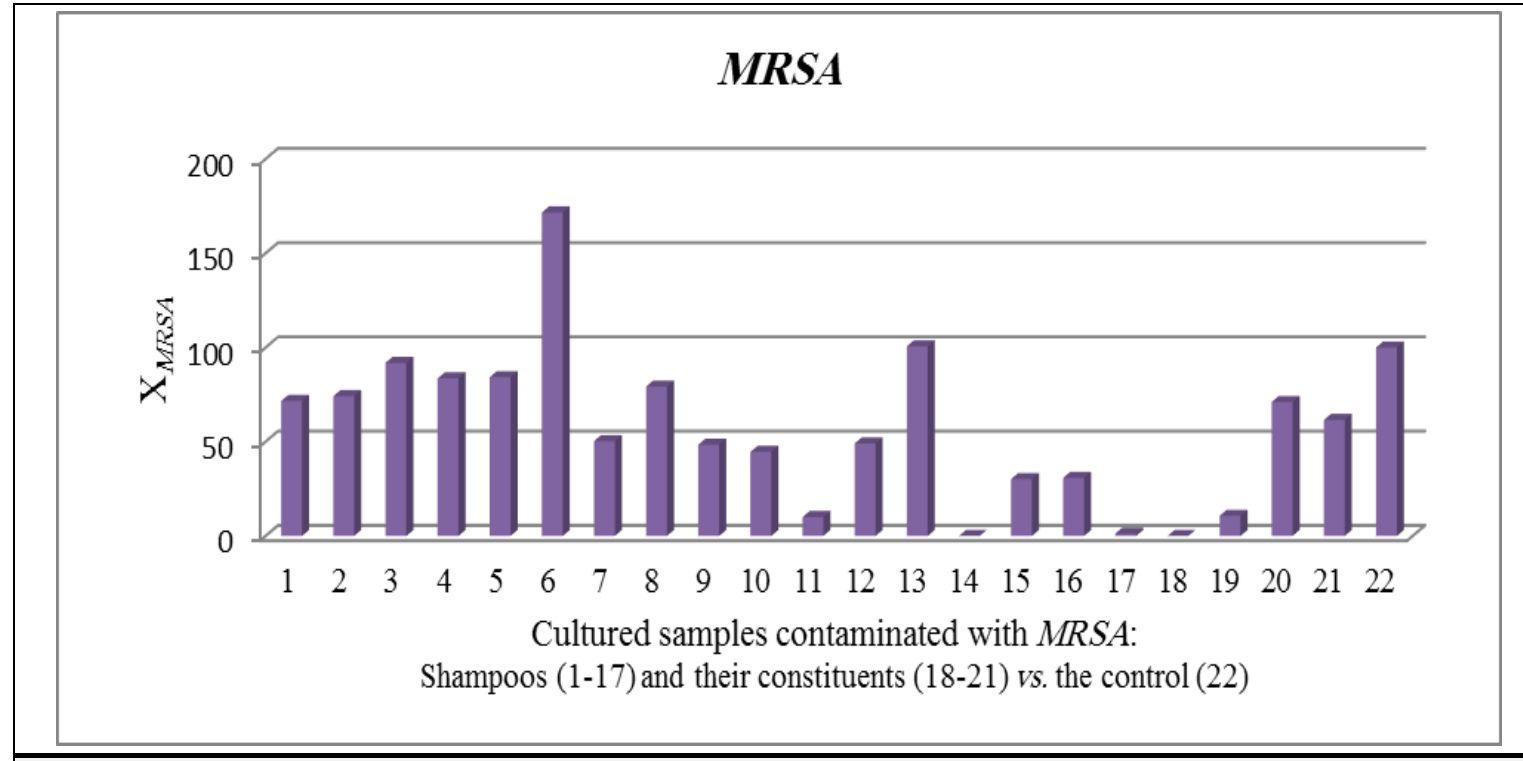

Figure 4. MRSA growth percentages $\left(\mathrm{X}_{M R S A}\right)$, upon thirty minutes adjacency to shampoo samples (117) or their constituents (18-21), all relative to the corresponding control bacterial assays not subjected to the shampoo formulations or their constituents (Sample 22)

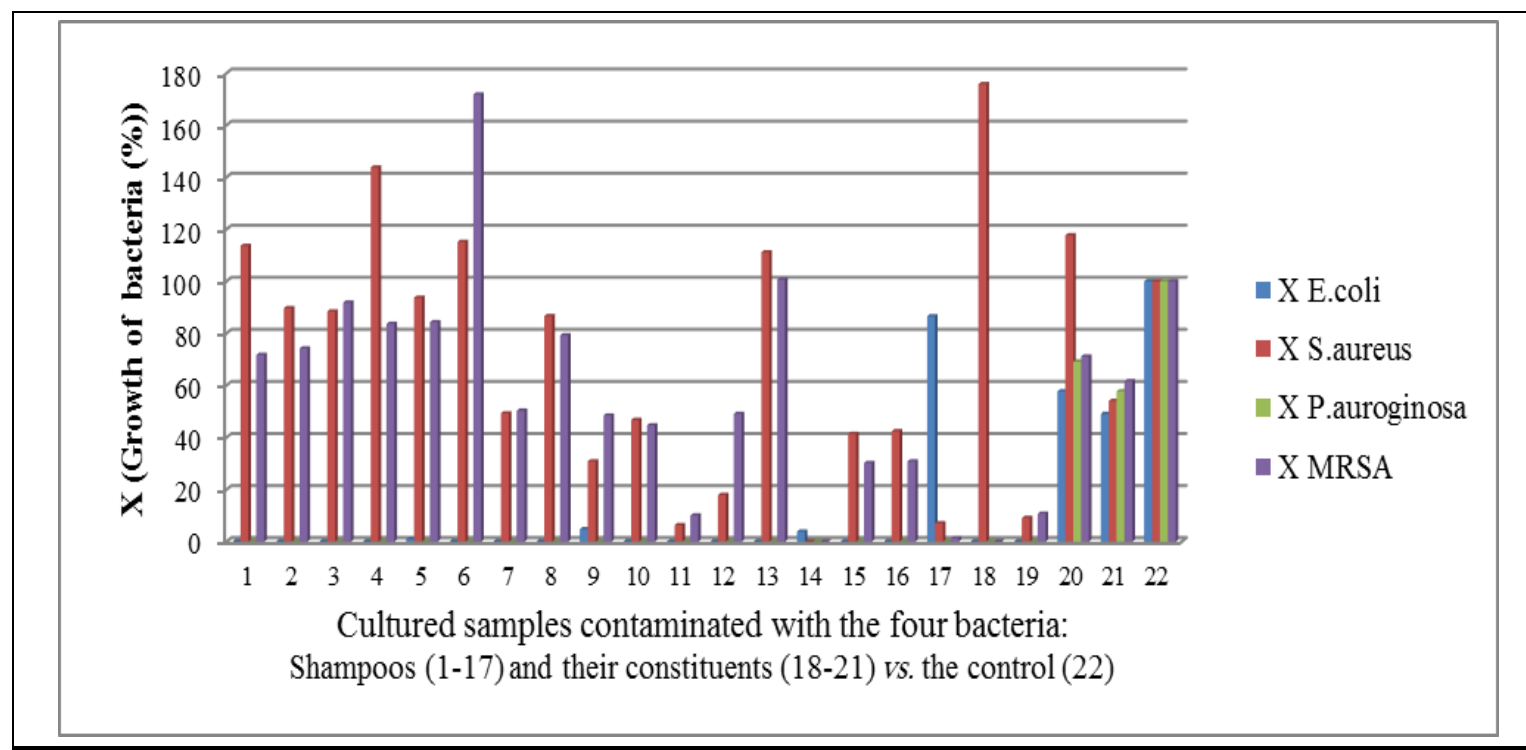

Figure 5. E. coli, S. aureus, P. aeruginosa, and MRSA growth percentages (X), upon thirty minutes adjacency to seventeen shampoo samples (1-17), along with four shampoo constituents (18-21), all relative to the corresponding control bacterial assay not subjected to the shampoo formulations or their constituents (Sample 22)

\section{Conclusion}

Preservative capacity is measured for seventeen currently accessible Iranian made shampoo products 1-17. Upon purchase, bacterial counts show no trace of any microbial contamination. After 40 days 
normal usage by seventeen volunteers, the allocated bottles are returned and their bacterial counts are repeated, under the same conditions. Surprisingly, no trace of any microbial contamination is observed. No antimicrobial activity is practically demonstrated by any of the four main ingredients of the shampoos including SLES, betaine, coconut fatty acid, and glycerin. Upon deliberate contamination of the seventeen brands; the factory employed preservatives [5-chloro-2-methyl-4isothiazolin-3-one and 2-methyl-4isothiazolin-3-one (KATHON CG)] immerge highly bactericidal against contaminants: $E$. coli, S. aureus, P. aeruginosa, and MRSA. Actually, all samples 1-17 are fully capable of killing a $10^{8}$ population of the above bacteria in one hour. The highest antibacterial activity is demonstrated by shampoo 14 after 30 minutes of contamination. Hence, shampoo 14 proves to be the most resistant against high concentration of the above mentioned bacteria.

\section{Acknowledgments}

The authors appreciate the financial support of this work by the Iran National Science Foundation (INSF) and Tarbiat Modares University. We are indebted to Dr. Mobarez group especially to Dr. Khoramabadi for his generous cooperation.

\section{Ethical approval}

In conformity with the publisher nonsolicitation regulations, each brand is given a numerical code (1-17) prior to the experimental work.

\section{Conflict of Interest}

The authors declare that they have no conflict of interest.

\section{References}

[1]. E. Smulders, W. Rybinski, E. Sung, W. Rähse, J. Steber, F. Wiebel, A. Nordskog; Laundry Detergents. In Ullmanns Encyclopedia of Industrial Chemicals, Bohnet M, Brinker CJ, Clemens H, Cornils B, Evans TJ, Greim H, Hegedus LL, Heitbaum J, Herrmann WA, Karst U, et al. Eds. Wiley-VCH Verlag GmbH: Weinheim, y 2009.

[2]. B. Fabry, Chemie in unserer Zeit. Tenside 1991, 4, 214-222.

[3]. U. Merrettig-Bruns, E. Jelen, Materials, 2009, 2, 181-206.

[4]. R.J. Farn, Chemistry and technology of surfactants. Blackwell Publishing Ltd, Oxford, England 2007.

[5]. K. Kosswig, Surfactants. In Ullmanns Encyclopedia of Industrial Chemicals, Bohnet M, Brinker CJ, Clemens H, Cornils B, Evans TJ, Greim H, Hegedus LL, Heitbaum J, Herrmann WA, Karst U, et al. Eds. Wiley-VCH Verlag GmbH, Weinheim, Germany 2009.

[6]. R. Saba, A. Adeel, H. Shahida, Afr. J. Biotechnol., 2009, 8, 1431-1436.

[7]. P. Hössel, R. Dieing, R. Nörenberg, A. 
Pfau, R. Sander, Int. J. Cosmet. Sci., 2000, 22, 1-10.

[8]. T.D. Ravita, R.S. Tanner, D.G. Ahearn, E.L. Arms, P.W. Crockett, J. Ind. Microbiol. Biotechnol., 2009, 36, 35-38.

[9]. L. Burr, Saint Martin's University Biology Journal 2006, 1, 117-128.

[10]. S.O. Olson, J. Soc. Cosm. Chem., 1967, 18, 191-198.

[11]. S. Wong, D. Street, S.I. Delgado, K.C. Klontz, J. Food Prot., 2000, 63(8), 11131116.

[12]. M.D. Lundov, C. Zachariae, Int.J. Cosmet. Sci., 2008, 30, 471-474.

[13]. A.A. Abdelaziz, M.S.E. Ashour, H. Hefni, O.M. El-Tayeb, J. Clin. Pharm. Ther., 1989, 14, 29-34.

[14]. T.A. Madani, S. Alsaedi, L. James, B.S. Eldeek, A.A. Jiman-Fatani, M.M. Alawi, D. Marwan, M. Cudal, M. Macapagal, R. Bahlas, M. Farouq, J. Hosp. Infect,. 2011, 78, 16-19. [15]. H.S. Al-Mijalli, International Conference on Medical Sciences and Chemical Engineering (ICMSCE'2013) August 28-29, 2013, Penang (Malaysia) 20-24.

[16]. Q. Abu Shaqra, Y. Mashni, W. AlMomani, JJBS., 2011, 4, 113-118.

[17]. R.A. Razooki, E.N. Saeed, H. Hamza, Iraqi. J. Pharm. Sci., 2009, 18, 20-25.
[18]. Rohm and Haas, Personal Care, 2007, PC0202006B.

[19]. Iranian codes of standards (No. 3271, ICS: 07.100.99; 71.100.70).

[20]. D.K. Brannan, J.C. Dille, Appl. Environ. Microbiol., 1990, 56, 1476-1479.

[21]. S. Khodaveisi, E. Ghahremani, P. Abdollahi, S. Soori, S. Moradzadeh, A. Shamadi, F. Mohammadi, N. Kiasat, Sci. J. Kurd. U. Med. Sci., 2014, 19, 123-129.

[22]. G.h. Jahed Khaniki, F. Ahmadi, S. Niazi, P. Kaseb, Investigating of fungal exuberance in baths of Tehran University of Medical Sciences dorms in 2012. 16 th $^{\text {th }}$ National Conference on Environmental Health 2013, Iran, Tabriz.

[23]. M.A. Carrie Hribar, Understanding concentrated animal feeding operations and their Impact on communities. National Association of Local Boards of Health, Ohio, U.S.A 2010.

[24]. A.R. Oller, L. Province, B. Curless, J. Athl. Train., 2010, 45, 222-229.

[25]. K. Botzenhardt, G. Doring, Ecology and epidemiology of Pseudomonas aeruginosa. "Pseudomonas aeruginosa as an Opportunistic Pathogen", 1993, 1-7. [26]. M. Schultz, SA Pharm. J., 2009, 1, 28-30.

How to cite this manuscript: Marzieh Miranzadeh, Mohammad Zaman Kassaee*, Leila Sadeghi, Analysis of Preservative Capacity for Contemporary Iranian Shampoos, Adv. J. Chem. $A, 2019,2(1), 45-56$. 